\title{
Comparative Study on Maximum Power Point Tracking Methods of Photovoltaic Cells
}

\author{
A.Q. Zhang, H. Liu, Y. Song, M. Dai \\ School of Mechanical, Electrical \& Information Engineering \\ Shandong University \\ Weihai, China
}

\begin{abstract}
In this paper, different methods were used to track the maximum power point of output power of photovoltaic cells (PV) by MATLAB/Simulink. First of all, the PV and Boost circuit models were built. The output change of voltage and current could be detected when light intensity was changed. Secondly, four circuits of Maximum Power Point Tracking (MPPT) of PV were designed. The four methods are perturbation and observation method, Incremental conductance method, fuzzy control method and neural network method. Then, all the models were built and simulated. According to simulation results, the maximum output power changed with light intensity differently. In the end, a comparative study of the maximum power output waveform of various methods was made. The experimental results show that using neural network method can complete MPPT more quickly and more accurately.
\end{abstract}

Keywords-PV; MPPT; MATLAB/Simulink; comparative research; result analysis

\section{INTRODUCTION}

With the exhaustion of fossil energy and the increasing environment problems, it is imminent to seek an energy that is sufficient and easy to use. As a free and renewable energy, the solar energy is more and more popular. Based on the photovoltaic effect, the PV can directly convert solar energy into electrical energy to be used by people and can alleviate the energy crisis.

However, low conversion rate and high cost seriously hinder the development of PV[1]. Therefore, it is very necessary to make researching on MPPT deeply.

\section{SIMULATION OF PV MODEL AND PRINCIPLE OF MPPT}

The equivalent circuit of PV is shown in Figure 1.

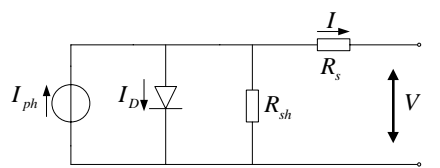

FIGURE I. EQUIVALENT CIRCUIT OF PV.

The output characteristic of PV is described as equation (1).

$$
I=I_{p h}-I_{D}\left\{\exp \left[q\left(V+I R_{s}\right) /(A k T)\right]-1\right\}-\left(V+I R_{s}\right) / R_{s h}
$$

Where $I$ is output current of $\mathrm{PV}, V$ is output voltage, $I_{p h}$ is photocurrent, $I_{D}$ is saturation current of diode, $q$ is charge of electron, $R_{s}$ is the series resistor, $R_{s h}$ is the parallel resistor, $A$ is characteristic factor of diode, $k$ is Boltzmann constant and $T$ is temperature of PV. This paper designs a practical engineering mathematical model of PV by using the software MATLAB/Simulink and is shown in Figure $2^{[2]}$.

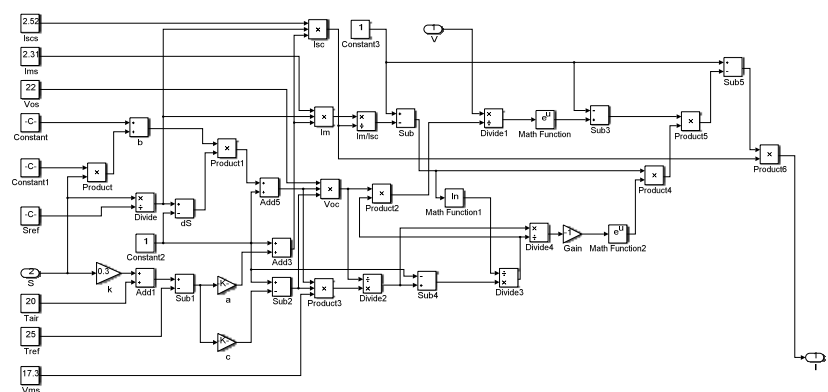

FIGURE II. DYNAMIC SIMULATION MODEL OF PV.

The electrical characteristic curve of PV is unimodal function and as shown in Figure 3.

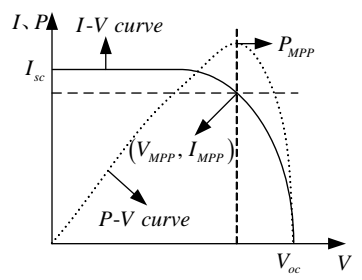

FIGURE III. ELECTRICAL CHARACTERISTICS OF PV.

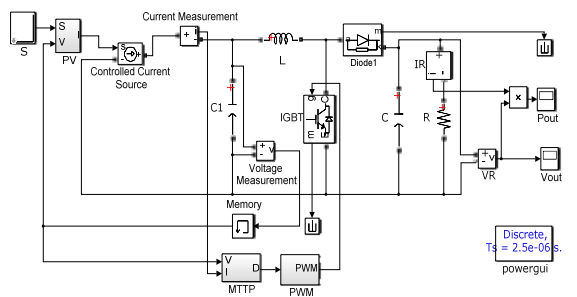

FIGURE IV. SIMULATION MODEL OF MPPT OF PV

In this Figure 3, $P$ is the output power of PV, $V_{M P P}$ and $I_{M P P}$ are voltage and current at the maximum output power point. The whole simulation model of MPPT of PV is shown as Figure $4^{[3]}$. 


\section{COMPARATIVE STUDY ON METHODS OF MPPT}

\section{A. Perturbation and Observation Method}

The flow chart of perturbation and observation method is shown as Figure 5[4].

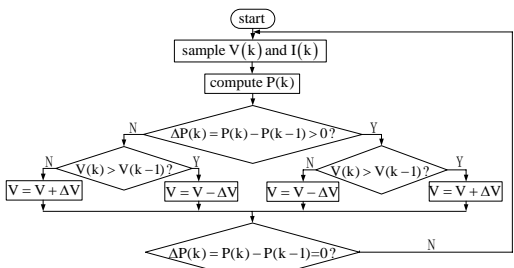

$$
\text { and }
$$

FIGURE V. FLOW CHART OF PERTURBATION AND OBSERVATION METHOD.

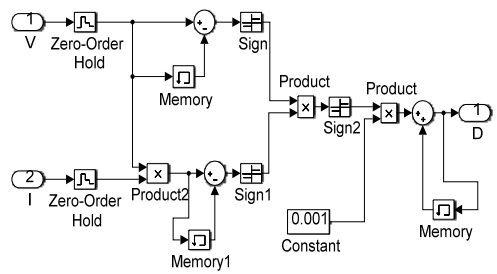

FIGURE VI. SIMULATION MODEL OF MPPT BASED ON PERTURBATION AND OBSERVATION METHOD.

Figure 6 is the MPPT control simulation model based on perturbation and observation method.

\section{B. Incremental Conductance Method}

The P-V characteristic curve of PV is shown in Figure 7.

Figure 8 is the flow chart of MPPT control[5].

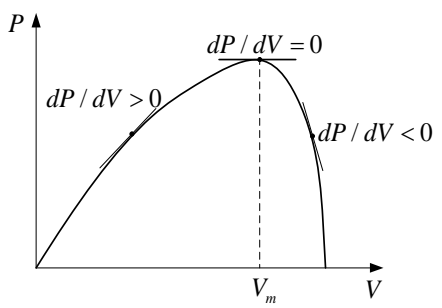

FIGURE VII. P-V CHARACTERISTIC CURVE OF PV.

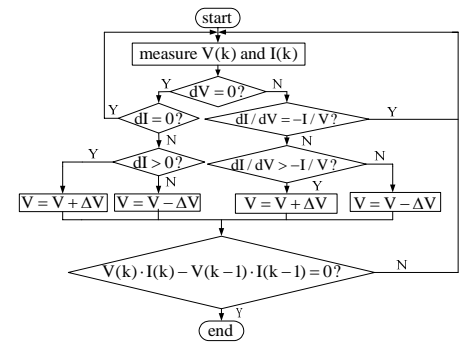

FIGURE VIII. FLOW CHART OF INCREMENTAL CONDUCTANCE METHOD.

Figure 9 is the simulation model of MPPT control based on incremental conductance method.

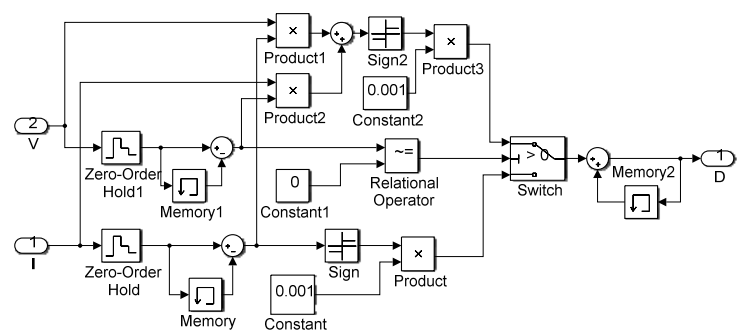

FIGURE IX. SIMULATION MODEL OF MPPT BASED ON INCREMENTAL CONDUCTANCE METHOD.

\section{Fuzzy Control Method}

This paper uses two-dimensional fuzzy controller and it determines that input variables are power variation $e(n)$ at $n$ time and the duty cycle step $a(n-1)$ at $n-1$ time, and output variable is the duty cycle step $a(n)$ at $n$ time. $E(n)$ is the value corresponding to $e(n)$ in the field of fuzzy set. The structure of fuzzy control is shown in Figure 10[6].

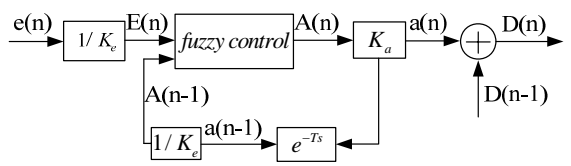

FIGURE X. STRUCTURE OF FUZZY CONTROL.

The range of $E(n), A(n)$ and $A(n-1)$ is [-3,3], [-1.5,1.5] and $[-3,3]$. Fuzzy sets are as follows ${ }^{[7]}$ :

$E(n)=\{N B, N M, N S, N O, P O, P S, P M, P B\} ; A(n)=\{N B, N M, N$ S,PS,PM,PB\};

\section{$A(n-1)=\{N B, N M, N S, P S, P M, P B\}$.}

Where NB, NM, NS, NO, PO, PS, PM, PB respectively represents high negative, moderate negative, small negative, negative zero, positive zero, small positive, moderate positive, large positive. The membership function of $e(n), a(n-1)$ and $a(n)$ are shown in Figure 11.

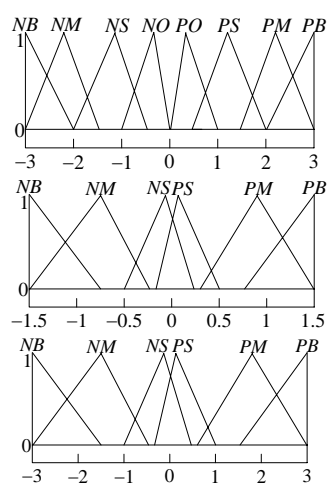

membership function of $e(n)$ membership function of $a(n-1)$ membership function of $a(n)$

FIGURE XI. MEMBERSHIP FUNCTION OF $e(n), a(n-1)$ AND $a(n)$.

The table of fuzzy control rules is obtained as Table 1 . 
TABLE I. TABLE OF FUZZY CONTROL RULES.

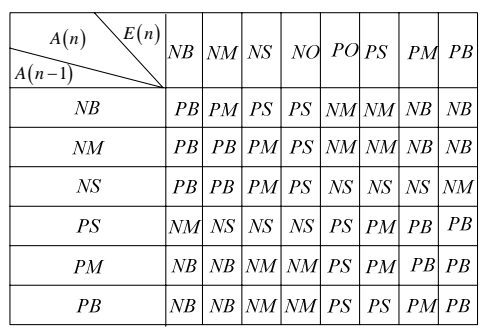

According to the conditions above, get the MPPT control simulation model based on fuzzy control as in Figure 12.

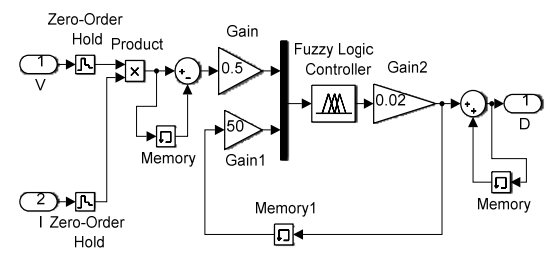

FIGURE XII. SIMULATION MODEL OF MPPT BASED ON FUZZY CONTROL.

\section{BP Neural Network Method}

Assuming that the number of neurons in input layer is $M$, hidden layer is I, and output layer is J. Then the network structure is as shown in Figure 13[8].

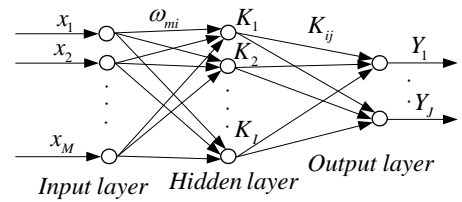

FIGURE XIII. STRUCTURE OF THREE-LAYER NEURAL NETWORK.

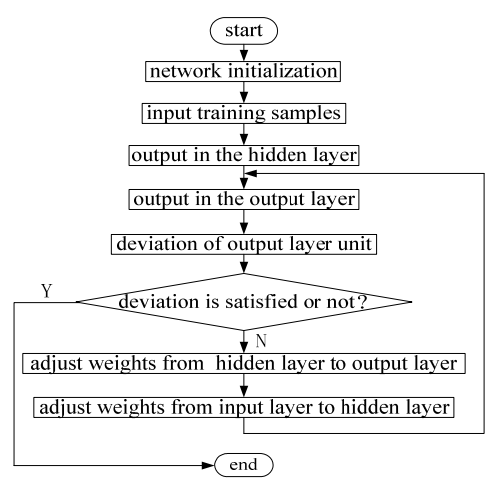

FIGURE XIV. FLOW CHART OF BP NEURAL NETWORK.

According to BP algorithm, flow chart of BP neural network algorithm as is shown in Figure 14[9].

In this paper, the input is light intensity, and the target vector is maximum power of PV in the neural network. The number of hidden layer is determined as five.

Using the neural network toolbox in MATLAB, design BP neural network, and programs are as follows:
$\mathrm{P}=0: 1: 1000 ; \mathrm{T}=\mathrm{P} ;$ net=newff(P,T,5);net.trainParam.Fcn='tra ingd';net.trainParam.goal=0.001;net=train(net, $\mathrm{T}) ; \mathrm{Y}=\operatorname{sim}($ net, $\mathrm{P})$;

After training, model of MPPT control based on neural network is shown as Figure 15.

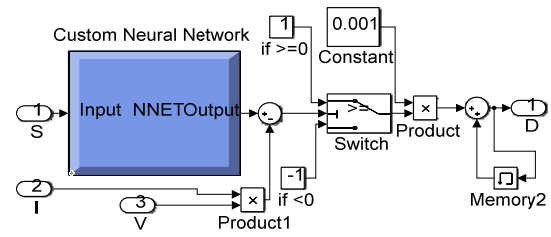

FIGURE XV. BP MPPT CONTROL MODEL OF NEURAL NETWORK.

\section{ANALYSIS ON SIMULATION RESULTS}

In this paper, as shown in Figure 1 , the temperature is $25^{\circ} \mathrm{C}$, and the light intensity turns into $950 \mathrm{~W} / \mathrm{m} 2$ from $750 \mathrm{~W} / \mathrm{m} 2$ at 0.1 second. In the Boost circuit, the value of $\mathrm{L}$ is $220 \mu \mathrm{H}, C_{1}$ is $50 \mu \mathrm{F}, C$ is $60 \mu \mathrm{F}$ and $\mathrm{R}$ is $12.8 \Omega$. The sampling period is set to $0.00001 \mathrm{~s}$. Using the algorithm ode23tb(stiff/TR-BDF2) with variable step size, the maximum and minimum step size, the initial step size and the absolute error is set to auto, and the relative error is set to $1 \mathrm{e}-3$, and then simulate it. The simulation result of each method of MPPT is shown as Figure 16 to 19.
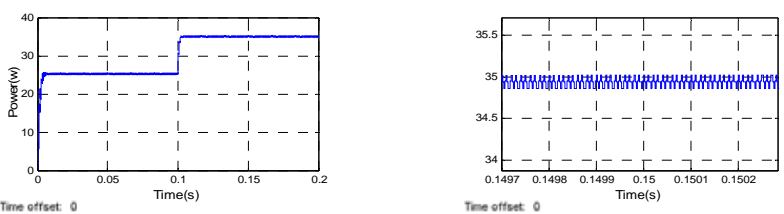

(a) Output power (b) Local amplification of output power

FIGURE XVI. SIMULATION RESULTS OF PERTURBATION AND OBSERVATION METHOD.


(a) Output power (b) Local amplification of output power FIGURE XVII. SIMULATION RESULTS OF INCREMENTAL CONDUCTANCE METHOD.
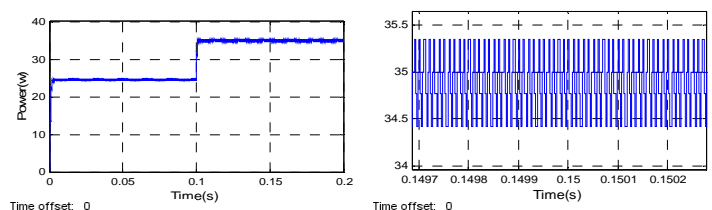

(a) Output power. (b) Local amplification of output power FIGURE XVIII. SIMULATION RESULTS OF FUZZY CONTROL METHOD. 

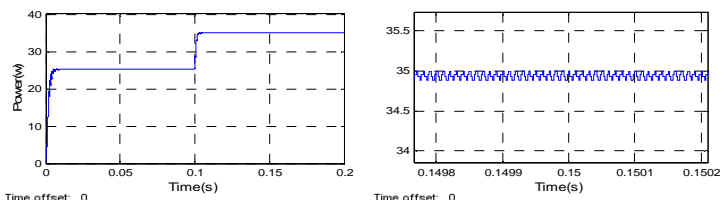

(a)Output power. (b)Local amplification of output power

METHOD.

Comparing results of each method of MPPT, the advantages and disadvantages are shown as in Table 2.

TABLE II. COMPARISON OF MPPT METHODS.

\begin{tabular}{ccc}
\hline $\begin{array}{c}\text { Perturbation and } \\
\text { observation }\end{array}$ & $\begin{array}{c}\text { less parameters, easy to } \\
\text { implement, fast tracking }\end{array}$ & $\begin{array}{c}\text { Easy to produce oscillations, bigger } \\
\text { power loss, can not take both } \\
\text { accuracy and response speed into } \\
\text { account }\end{array}$ \\
Incremental conductance & $\begin{array}{c}\text { Weak oscillation, small } \\
\text { power loss }\end{array}$ & $\begin{array}{c}\text { Slow response speed, complex } \\
\text { structure }\end{array}$ \\
Fuzzy control & $\begin{array}{c}\text { Fast response, easy to cooperate with } \\
\text { other methods to achieve fast and } \\
\text { accurate tracking of maximum power }\end{array}$ & $\begin{array}{c}\text { Strong oscillation, bigger power } \\
\text { loss }\end{array}$ \\
Neural network & $\begin{array}{c}\text { Fast response, weaker } \\
\text { oscillation, smaller power loss }\end{array}$ & $\begin{array}{c}\text { Need to get training samples, } \\
\text { complex design }\end{array}$ \\
\hline
\end{tabular}

\section{CONCLUSION}

MPPT can effectively improve electric efficiency of PV. According to mathematical model of $\mathrm{PV}$, this paper builds a PV simulation model by MATLAB/Simulink. The whole simulation model combined PV, Boost circuit and MPPT is built. Four different methods are used to realize MPPT, and advantages and disadvantages of each method are obtained through simulation results. It shows that the effect of neural network is best. Through theoretical analysis, the results of the combining of fuzzy control and incremental conductance method will be better.

The research and study in this paper has a great significance on study and application of MPPT. A further study can be made on the basis of this paper, which can develop a control method that is ideal on all aspects.

\section{ACKNOWLEDGMENTS}

This work is supported by the National Natural Science Foundation of China (No. 61473174, 61105100, 51376110).

\section{REFERENCES}

[1] X.F. Han, Research of photovoltaic MPPT composite control based on neural network and fuzzy control[D]. Nanchang Aeronautical University, 2013.

[2] J.Y. Gao, X.H. Gong, F.L. Wang, B. Dong \& C. Di, Simulation research on photovoltaic cell Based on Matlab/Simulink[J]. Power Grid and Clean Energy, 29(3), pp. 91-96, 2013.

[3] P. Sun, The modelling and Simulation of Photovoltaic cells based on MPPT control strategy[J]. Journal of State Grid Technology College, 17(1), pp. 6-10, 2014.

[4] Q. Tang, Maximum power tracking control of photovoltaic power generation system[D]. Shanxi University, 2011.

[5] L.G. Liu, Study on the system of maximum power tracking control of photovoltaic power generation[D]. Yanshan University, 2011.

[6] J. Chen \& J. Hui, MPPT of photovoltaic power generation technology based on fuzzy control strategy[J]. Modern electronic technology, 2009, (06).

[7] D.S. Lai, Maximum power tracking control based on fuzzy control[J]. the Electronic World, 2011.

[8] M. Chen, The neural network and the example[M]. Tsinghua University press: Beijing, PP. 79-81, 2013.

[9] L.X. Wang, Comparative study of maximum power point tracking photovoltaic based on BP and RBF neural network[D]. Shantou University, 2010. 